\title{
Mitochondrial damage-induced impairment of angiogenesis in the aging rat kidney
}

\author{
Minoru Satoh, Sohachi Fujimoto, Hideyuki Horike, Masahito Ozeki, Hajime Nagasu, Naruya Tomita, \\ Tamaki Sasaki and Naoki Kashihara
}

Decreased expression of vascular endothelial growth factor (VEGF) in the renal tubules is thought to cause progressive loss of the renal microvasculature with age. Mitochondrial dysfunction may be a principal phenomenon underlying the process of aging. The relation between VEGF expression and mitochondrial dysfunction in aging is not fully understood. We hypothesized that mitochondrial dysfunction blocks VEGF expression and contributes to impaired angiogenesis in the aging kidney. The aim of this study was to assess the role of mitochondria in VEGF expression in the aging rat kidney. We evaluated the accumulation of 8-hydroxy-2'-deoxyguanosine in mitochondrial DNA, as well as mitochondrial dysfunction, as assessed by electron microscopy of mitochondrial structure and histochemical staining for respiratory chain complex IV, in aging rat kidney. An increase in hypoxic area and a decrease in peritubular capillaries were detected in the cortex of aging rat kidneys; however, upregulation of VEGF expression was not observed. The expression of VEGF in proximal tubular epithelial cells in response to hypoxia was suppressed by the mitochondrial electron transfer inhibitor myxothiazol. Mitochondrial DNA-deficient cells also failed to upregulate VEGF expression under hypoxic conditions. These results indicate that impairment of VEGF upregulation, possibly as a result of mitochondrial dysfunction, contributes to impaired angiogenesis, which in turn leads to renal injury in the aging rat kidney.

Laboratory Investigation (2011) 91, 190-202; doi:10.1038/labinvest.2010.175; published online 4 October 2010

KEYWORDS: angiogenesis; hypoxia-inducible factor-1; mitochondria; reactive oxygen species; vascular endothelial growth factor

Healthy elderly individuals without other identifiable renal disease show a decrement in the glomerular filtration ratio of approximately $2 \mathrm{ml} / \mathrm{min} /$ year, presumably as a result of aging nephropathy. ${ }^{1}$ The presence of mild chronic kidney disease enhances the risk for cardiovascular disease, bone disease, frailty, and adverse drug reactions and increases morbidity and mortality. ${ }^{2,3}$ Elucidation of the mechanisms of renal dysfunction accompanying aging may be useful in the prevention or progression of chronic kidney disease and cardiovascular disease. Aging-specific structural changes have been identified in the kidney; the glomerular basement membrane thickens, and mesangial sclerosis and tubulointerstitial fibrosis have been reported in rodents, dogs, pigs, baboons, and humans. ${ }^{4}$ Loss of the microvasculature as a result of changes in the local production of angiogenic factors is associated with age-related structural and functional changes in rat kidney. For example, decreased expression of vascular endothelial growth factor (VEGF) and increased expression of thrombospondin- 1 in the tubules has been reported to cause progressive loss of the renal microvasculature. ${ }^{5}$ However, the mechanisms of decreased angiogenesis have not been fully elucidated.

Normal mitochondrial function is imperative for optimal energy production. ${ }^{6}$ Aging cells have a diminished ability to produce ATP, owing to changes in mitochondrial structure and function. Therefore, mitochondrial dysfunction may be a principal phenomenon underlying the process of aging. Mitochondria are thought to be involved in oxygen sensing. It has been suggested that the electron transport chain functions as an $\mathrm{O}_{2}$ sensor by releasing reactive oxygen species (ROS) from complex III in response to hypoxia. ${ }^{8,9}$ Oxidative stress increases with aging, and the accumulation of oxidative damage to mitochondrial DNA appears to be involved in the aging phenotype. Thus, impairment of mitochondria

Division of Nephrology and Hypertension, Department of Internal Medicine, Kawasaki Medical School, Okayama, Japan

Correspondence: Dr M Satoh, MD, PhD, Division of Nephrology and Hypertension, Department of Internal Medicine, Kawasaki Medical School, 577 Matsushima, Kurashiki, Okayama 701-0192, Japan.

E-mail: msatoh@med.kawasaki-m.ac.jp

Received 29 March 2010; revised 24 August 2010; accepted 30 August 2010 
in response to oxidative stress accumulation may decrease mitochondrial oxygen sensing. We hypothesized that mitochondrial dysfunction induced by oxidative stress impairs angiogenesis in the aging kidney, resulting in tubulointerstitial damage. To elucidate whether mitochondrial dysfunction and impaired angiogenesis are present in the aging rat kidney, we compared renal morphology and mitochondria in old versus young rats. We also assessed the role of mitochondria in VEGF expression in cultured proximal tubular epithelial cells.

\section{MATERIALS AND METHODS Materials}

Wistar rats were purchased from Charles River Japan (Kanagawa, Japan). Antibody against rat endothelial cell antigen 1 (RECA-1; MCA970GA) was from AbD Serotec MorphoSys UK (Oxford, UK). The Hypoxyprobe-1 Kit containing solid pimonidazole $\mathrm{HCl}$ and mouse monoclonal antibody was from Hypoxyprobe (Burlington, MA, USA). Antibody against VEGF (sc-507) and normal rabbit IgG (sc-2027) were from Santa Cruz Biotechnology (Santa Cruz, CA, USA), and anti-nitrotyrosine antibody (\#06-284) was from Millipore Corp. (Billerica, MA, USA). Anti-malondialdehyde (MDA) antibody, anti-8-hydroxy-2'-deoxyguanosine (8-OHdG) antibody, and the enzyme-linked immunosorbent assay (ELISA) kit for 8-OHdG were from the Japan Institute for the Control of Aging (Shizuoka, Japan). The chromatin immunoprecipitation (ChIP)-grade polyclonal hypoxiainducible factor-1 (HIF-1) $\alpha$-antibody (ab2185) was from Abcam (Cambridge, MA, USA). The Histofine Simple Stain MAX-PO kit was from Nichirei (Tokyo, Japan). Antibodies against p38 mitogen-activated protein kinase (p38 MAPK; \#9212), phospho-p38 MAPK (\#9211), AMP-activated protein kinase (AMPK; \#2532), and phospho-AMPK (\#2531) were from Cell Signaling Technology (Danvers, MA, USA). The Human VEGF ELISA kit was from Thermo Scientific (Rockford, IL, USA). The Mitochondrial DNA Isolation Kit was from BioVision. (Mountain View, CA, USA). The One Day ChIP assay kit was from Nippon Gene (Tokyo, Japan). Normal human proximal tubular epithelial cells (hPTECs), culture medium (REBM), and the additional factor set (REGM SingleQuots Supplements and Growth Factors) were from Lonza Walkersville (Walkersville, MD, USA). Primers for PCR and real-time (RT)-PCR and probes for RT-PCR were from Sigma-Genosys (Hokkaido, Japan). Other reagents were locally available and of analytic grade. RT-PCR reagents were from Takara Bio (Otsu, Shiga, Japan). Amersham ECL Plus Western Blotting Detection Reagents and Amersham Hyperfilm ECL were from GE Healthcare Japan (Tokyo, Japan).

\section{Animals}

Male Wistar rats were used for this study. Rats of two age groups ( 4 months old, $n=10$; 24 months old, $n=10$ ) were housed one per cage in a room maintained at $21^{\circ} \mathrm{C}$ to $24^{\circ} \mathrm{C}$ with a 12:12-h light-dark cycle and fed standard rat chow and water ad libitum. The experimental protocol (no. 06-029) was approved by the Animal Research Committee of Kawasaki Medical School and was conducted according to the Guide for the Care and Use of Laboratory Animals of Kawasaki Medical School based on the National Institutes of Health Guide for the Care and Use of Laboratory Animals (NIH Publications No. 80-23, revised 1996). All efforts were made to minimize animal suffering, to reduce the number of animals used, and to utilize alternatives for the in vivo techniques, if available. One week before tissue harvesting, body weight was recorded, and blood pressure was measured by the tail-cuff method with an automatic sphygmomanometer (BP98A; Softron, Tokyo, Japan), and rats in both age groups were placed in metabolic cages for $24 \mathrm{~h}$ to collect urine. All rats received injection of pimonidazole $(60 \mathrm{mg} / \mathrm{kg})$ by means the tail vein, followed $2 \mathrm{~h}$ later by anesthesia with pentobarbital $(50 \mathrm{mg} / \mathrm{kg}$, intraperitoneal) and sevoflurane (5\%, inhalation), blood was collected through cardiac puncture, and the kidneys were removed by a midperitoneal incision. Pimonidazole injection did not interfere with any of the other measurements (Supplementary Figure 1). Half of each left kidney was cut in cross-section and fixed in $4 \%$ paraformaldehyde, and the remaining half was used for the preparation of unfixed cryostat sections. A sample of cortical tissue from each right kidney was snap-frozen in liquid nitrogen and stored at $-80^{\circ} \mathrm{C}$ for subsequent RNA, mitochondrial DNA (mtDNA), and protein assays. Proteinuria and creatinine levels in serum and urine were measured by SRL (Tokyo, Japan).

\section{ELISA for Urinary 8-OHdG}

The amount of 8 -OHdG in urine was measured with a competitive ELISA kit (Japan Institute for the Control of Aging) after protein exclusion with a 10000 molecular weight cut-off mesh to avoid interference by urinary protein.

\section{Renal Histopathology}

For light microscopy, paraffin-embedded sections $(4-\mu \mathrm{m}$ thickness) were stained with Masson-trichrome. Tubulointerstitial injury was graded according to the extent of tubular and interstitial damage compared with areas of normal architecture $(0=$ no change; $1=<25 \% ; 2=25 \%-$ $50 \% ; 3=50 \%-75 \% ; 4=75 \%-100 \%)$. For each section, the entire cortical and juxtamedullary regions were evaluated. The severity of glomerular injury was evaluated according to sclerotic lesions in the glomeruli $(0=$ no change; $1=<25 \%$; $2=25 \%-50 \% ; 3=50 \%-75 \% ; 4=75 \%-100 \%$ ). A totsl of 50 glomeruli were randomly selected from each rat, and the mean score was calculated. Tissues were also processed for electron microscopy as described previously ${ }^{10}$ to assess ultrastructural alterations in the mitochondria.

\section{Immunohistochemistry}

Paraffin sections (4- $\mu \mathrm{m}$ thickness) were used for immunohistochemical studies, with the exception of RECA-1 
staining, which used cryostat sections. Anti-RECA-1, antipimonidazole, anti-VEGF, anti-MDA, anti-nitrotyrosine, and anti-8-OHdG antibodies were applied to renal sections overnight at $4{ }^{\circ} \mathrm{C}$. Antibody binding was detected with the Histofine Simple Stain MAX-PO kit and diaminobenzidine (Sigma-Aldrich Japan, Tokyo, Japan). The percent positive area was measured with a color image analyzer (WinLoof; Mitani, Fukui, Japan). A total of 20 consecutive fields from each kidney were evaluated randomly at a magnification of $\times 100$.

\section{Cytochrome c Oxidase (COX) Staining}

To examine mitochondrial respiratory activity in vivo, COX staining was performed as described previously. ${ }^{11}$ The percent positive area was measured with a color image analyzer. A total of 20 consecutive fields from each kidney were evaluated randomly at a magnification of $\times 100$.

\section{Oligonucleotide Microarray Hybridization and Data Analysis}

Gene expression profiling of rat kidneys was performed with the GeneChip Rat Genome 2302.0 array (Affymetrix, Santa Clara, CA, USA). Each sample subjected to microarray hybridization consisted of total RNA extracted from the renal cortex of both 4-month-old and 24-month-old rats. All procedures for microarray analysis were carried out by Kurabo Industries, Bio-Medical Department (Osaka, Japan). Gene expression data were analyzed with GeneSpring GX software (Agilent Technologies, Santa Clara, CA, USA).

\section{Quantitative RT-PCR of Mitochondrial mRNA Expression} Isolation of RNA and quantitative RT-PCR were performed as described previously. ${ }^{12}$ Primers and probes for TaqMan analysis were designed with Primer 3 online software (http:// frodo.wi.mit.edu/primer3/; accessed 1 January 2010) based on sequence information from GenBank. Primers and probes are listed in Supplementary Figure 2. The level of expression in each sample was expressed according to that of the housekeeping gene glyceraldehyde-3-phosphate dehydrogenase or $18 S$ ribosomal RNA.

\section{Mitochondrial DNA Short- and Long-Extension PCR Amplification}

The mtDNA was isolated from rat renal cortex with a mitochondrial DNA kit according to the manufacturer's protocol. Long-range PCR was used to co-amplify long and short mtDNA fragments. ${ }^{13}$ The PCR products were electrophoresed on $1 \%$ agarose gels and stained with ethidium bromide to visualize the 8636 -bp and 316-bp DNA products. Band intensity was measured with a PhosphorImager (Molecular Dynamics, Sunnyvale, CA, USA), and the ratio of long to short DNA fragments was calculated.

\section{Cell Culture}

Normal hPTECs were maintained in REBM with REGM SingleQuots at $37^{\circ} \mathrm{C}$ in $5 \% \mathrm{CO}_{2}$. Mitochondrial DNAdepleted $(\rho 0)$ hPTECs were prepared essentially according to King and Attardi. ${ }^{14}$ The oxygen concentration was changed to $21 \% \mathrm{O}_{2}$ (room air), $5 \% \mathrm{O}_{2}$, or $2 \% \mathrm{O}_{2}$ hypoxia by adjusting the settings of the $\mathrm{CO}_{2}$ incubator. In some experiments, hPTECs were pretreated with myxothiazol $2 \mathrm{~h}$ before hypoxia. The hPTECs were incubated at different $\mathrm{O}_{2}$ concentrations for $2 \mathrm{~h}$ to $24 \mathrm{~h}$ ( $2 \mathrm{~h}$ for western blot analysis, $4 \mathrm{~h}$ for ChIP assay, and $24 \mathrm{~h}$ for VEGF immunostaining).

\section{ELISA for VEGF}

Supernatant was collected from the culture medium, and VEGF concentration was determined with an ELISA kit according to the manufacturer's protocol.

\section{ChIP Assay}

The ChIP assay was performed with a One Day ChIP kit, according to the manufacturer's protocol. In brief, cultured cells were cross-linked with formaldehyde. Fragmented chromatin was then immunoprecipitated with a rabbit polyclonal HIF- $1 \alpha$ antibody. Rabbit IgG was used as a negative control. The input was the supernatant from the no antibody control. The region from -1140 to -788 of the VEGF promoter was amplified by PCR from immunoprecipitated chromatin with the following primers: sense, 5'-GCGGGTAGGTTTGAATCATC-3'; antisense, 5'-GC CTGCAGACATCAAAGTGA-3'. The 353-bp PCR product was resolved on a $1.2 \%$ agarose gel and visualized by ethidium bromide staining and ultraviolet illumination. Signals were quantified by densitometry. Band intensity was measured with a PhosphorImager, and the ratio to input was calculated.

\section{Western Blot Analysis}

Rat renal samples or cultured hPTECs were homogenized on ice in $1 \mathrm{ml}$ of lysis buffer containing protease inhibitors and centrifuged at $8000 \mathrm{~g}$ for $10 \mathrm{~min}$. The protein concentration of the supernatants was determined with a Bio-Rad protein assay kit, and $40 \mu \mathrm{g}$ to $60 \mu \mathrm{g}$ of protein was subjected to western blot to with appropriate antibodies to determine the levels of nitrotyrosine, phosphorylated p38 MAPK, total p38 MAPK, phosphorylated AMPK, and total AMPK. Signals were visualized with Amersham ECL Plus Western Blotting Detection Reagents, captured on Amersham Hyperfilm ECL, and scanned and quantified by densitometry. Coomassie brilliant blue staining of the membrane confirmed equal loading and transfer.

\section{Statistical Analysis}

Values are expressed as mean \pm s.e.m. Statistical comparisons were made by one-factor analysis of variance with a TukeyKramer test for multiple comparisons or a Welch $t$-test, as appropriate. The level of significance was set at $P<0.05$. 


\section{RESULTS}

\section{Physiological Changes in Aged Rats}

Physiological characteristics of young (4-month-old) and old (24-month-old) rats are listed in Table 1. No significant difference was observed in the kidney weight /body weight ratio between young and old rats. However, old rats showed significantly increased body weight, mean blood pressure, and serum creatinine and decreased creatinine clearance compared with young rats. Old rats also showed significantly higher levels of urinary protein and 8-OHdG excretion compared with young rats.

\section{Tubulointerstitial Damage and Peritubular Capillary Loss in the Aging Rat Kidney}

Renal histological changes accompanying aging were assessed by Masson-trichrome staining. An increase in tubulointerstitial injury, including tubular atrophy and interstitial fibrosis, was observed in old versus young rats (Figure 1a and $\mathrm{b}$ ). The injury score showed a statistically significant increase in old versus young rats (Figure 1c). Peritubular capillaries were assessed by staining for RECA-1. The RECA-1 antibody reacts with rat endothelial cell surface antigen, thereby staining the peritubular capillary endothelium. In old rats, a significant decrease in the peritubular capillary area was detected compared with that in young rats (Figure 1d and e). The RECA-1-positive area, as an index of peritubular capillary volume, showed a statistically significant decrease in old versus young rats (Figure 1f). Glomerular injury, including sclerotic change, was observed in old rats (Figure $1 \mathrm{~g}$ and $\mathrm{h}$ ). The injury score showed a statistically significant increase in old versus young rats (Figure 1i).

Table 1 Physiological characteristics of 4-month-old versus 24-month-old rats

\begin{tabular}{lcc}
\hline Characteristic & $\begin{array}{c}4 \text { months } \\
(n=10)\end{array}$ & $\begin{array}{c}24 \text { months } \\
(n=10)\end{array}$ \\
\hline Body weight, g & $332 \pm 10$ & $474 \pm 35^{\mathrm{a}}$ \\
Left kidney weight, g & $3.2 \pm 0.1$ & $4.2 \pm 0.9$ \\
Left kidney/body weight ratio, \% & $0.96 \pm 0.07$ & $0.89 \pm 0.05$ \\
Mean blood pressure, mm Hg & $92 \pm 8$ & $111 \pm 10^{\mathrm{a}}$ \\
Serum creatinine, mg oer 100 ml & $0.21 \pm 0.02$ & $0.58 \pm 0.23^{\mathrm{a}}$ \\
Creatinine clearance, $\mathrm{ml} / \mathrm{min}$ per 100 g & $1.09 \pm 0.09$ & $0.55 \pm 0.04^{\mathrm{a}}$ \\
body weight & & \\
Urinary protein excretion, mg/day & $13 \pm 4$ & $232 \pm 89^{\mathrm{a}}$ \\
Urinary 8-OHdG excretion, ng/day & $7.7 \pm 5.9$ & $46.5 \pm 5.4^{\mathrm{a}}$ \\
\hline
\end{tabular}

Abbreviation: 8-OhdG, 8-hydroxy-2'-deoxyguanosine.

Values are expressed as mean \pm s.e.m.

${ }^{\mathrm{a}} P<0.05$ versus 4 months.

\section{Interstitial Hypoxia and VEGF Production in the Aging Rat Kidney}

To determine whether a decrease in peritubular capillary volume results in tubular hypoxia, we assessed tubulointerstitial tissue hypoxia with the use of the bioreductive hypoxia marker pimonidazole. In young rat kidney, hypoxia was observed only in the medullary area (Figure 2a). However, in old rat kidney, hypoxia spread to the cortical area (Figure 2b). The pimonidazole-positive area in the cortex showed a statistically significant increase in old versus young rats (Figure 2c). In general, VEGF expression increases in correspondence with hypoxia, resulting in a promotion of angiogenesis. However, despite the increase in renal hypoxic area, VEGF upregulation was not observed (Figure $2 \mathrm{~d}$ and e). On the contrary, the VEGF-positive area showed a statistically significant decrease in old versus young rats (Figure 2f). Microarray data also showed decreases in VEGF-A, VEGF-B, and VEGF receptor-2 expression in old rat kidney (Table 2). RT-PCR data also indicated that expression levels of VEGF-A, $V E G F-B$, and VEGF receptor-2 were significantly decreased in aged rat kidney (Table 3).

\section{Accumulation of Oxidative Stress in the Aging Rat Kidney}

To determine whether oxidative stress is increased in the aging rat kidney, we performed immunohistochemistry for the oxidative stress markers MDA, nitrotyrosine, and 8-OHdG. Figure $3 \mathrm{a}$ and $\mathrm{b}$ show representative immunohistochemical results for MDA, one of the final products of polyunsaturated fatty acid peroxidation. There were few MDA-positive tubules in young rats and an increase in old rats. The MDA-positive area showed a statistically significant increase in old versus young rats (Figure $3 \mathrm{c}$ ). Nitrotyrosine, a product of tyrosine nitration mediated by the peroxynitrite anion, was also increased in cortical tubules in old rats compared with young rats (Figure $3 \mathrm{~d}$ and e). In old rats, greater than $60 \%$ of the cortical area was positive for nitrotyrosine staining (Figure 3f). The nitrotyrosine protein level was also examined by western blot (Figure $3 j$ ). It was also significantly increased in old compared with young rat kidney. 8-OHdG is one of the major forms of DNA damage, including mtDNA, induced by ROS. Weak tubular staining for 8 -OHdG was observed in young rats (Figure $3 \mathrm{~g}$ ). In contrast, marked staining for 8-OHdG was observed in surviving tubules in old rats (Figure $3 \mathrm{~h}$ ). The 8-OHdG-positive area in the cortex showed a statistically significant increase in old versus young rats (Figure 3i). Microarray data also showed decreased expression of antioxidant genes, with the exception of superoxide dismutase 3, in the aged rat kidney (Table 4). RT-PCR data also indicated that expression levels of catalase, superoxide dismutases 1 and 2, thioredoxin reductases 1 and 2, and glutathione reductase were significantly decreased in aged rat kidney (Table 5). 

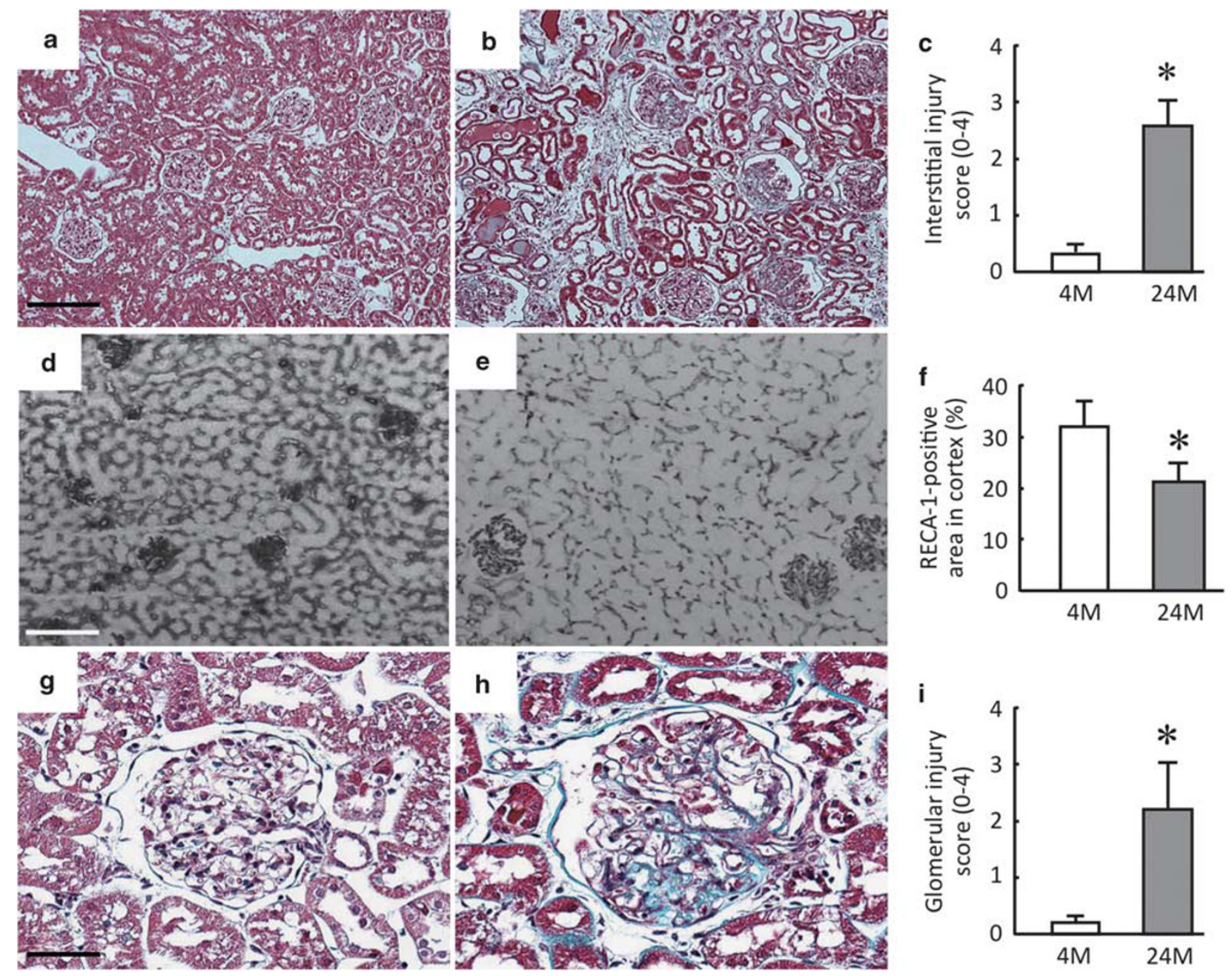

Figure 1 Tubulointerstitial damage and peritubular cell loss in aging kidney. (a, b) Masson-trichrome staining showing renal cortical morphology in 4-month-old (4M; a) and 24-month-old (24M; b) rats. Bar $=100 \mu \mathrm{m}$. (c) Interstitial injury score. $n=10$ for each group. Values are expressed as mean \pm s.e.m. ${ }^{*} P<0.05$ versus $4 \mathrm{M}$. (d, e) Staining for rat endothelial cell antigen (RECA)- 1 in cortical peritubular cells in $4 \mathrm{M}$ (d) and $24 \mathrm{M}(\mathbf{e})$ rats. Bar $=100 \mu \mathrm{m}$. (f) Percent volume of peritubular cells in renal cortex. $n=10$ for each group. Values are shown as mean \pm s.e.m. ${ }^{\star} P<0.05$ versus $4 \mathrm{M}$. (g, $\left.\mathbf{h}\right)$ Masson-trichrome staining showing glomerular morphology in 4-month-old (4M; g) and 24-month-old (24M; h) rats. Bar $=50 \mu \mathrm{m}$. (i) Glomerular injury score. $n=10$ for each group. Values are expressed as mean \pm s.e.m. ${ }^{*} P<0.05$ versus $4 \mathrm{M}$.

\section{Mitochondrial Damage in the Aging Rat Kidney}

Next, we determined whether oxidative stress is involved in the observed age-associated deficits in tubular mitochondrial function and changes in mitochondrial morphology. The mitochondrial genome encodes 13 essential members of the respiratory chain. Among these, mRNA expression of nicotinamide adenine dinucleotide dehydrogenase subunit 1 , nicotinamide adenine dinucleotide dehydrogenase subunit 2 , and cytochrome $b$ were examined by quantitative RT-PCR (Figure $4 \mathrm{a}-\mathrm{c}$ ). All of these genes showed decreased expression in old versus young rats. To determine the presence of deleted mtDNA molecules in kidney samples from old rats compared with young rats, long-extension PCR and short-extension PCR of mtDNA were performed (Figure 4d). The PCR products of long-extension PCR, but not short-extension PCR, were decreased in old rat kidney mtDNA compared with those in young rat kidney, indicating deletions of mtDNA in kidney were associated with aging.

Cells deficient in COX are biomarkers of mtDNA defects. Therefore, we performed histochemistry for COX. Histochemical staining for COX in young rat kidney yielded an intense, fine granular pattern in the tubular cells (Figure 4h). However, proximal tubular COX reactivity in old rat kidney was markedly decreased in most tubules (Figure 4i). Some tubules showed faint reactivity, whereas the majority were completely nonreactive. The COX-positive area showed a statistically significant decrease in old rats compared with young rats (Figure $4 \mathrm{~g}$ ). As mitochondrial dysfunction worsens, changes in mitochondrial morphology occur. Therefore, we assessed mitochondrial morphology by electron 

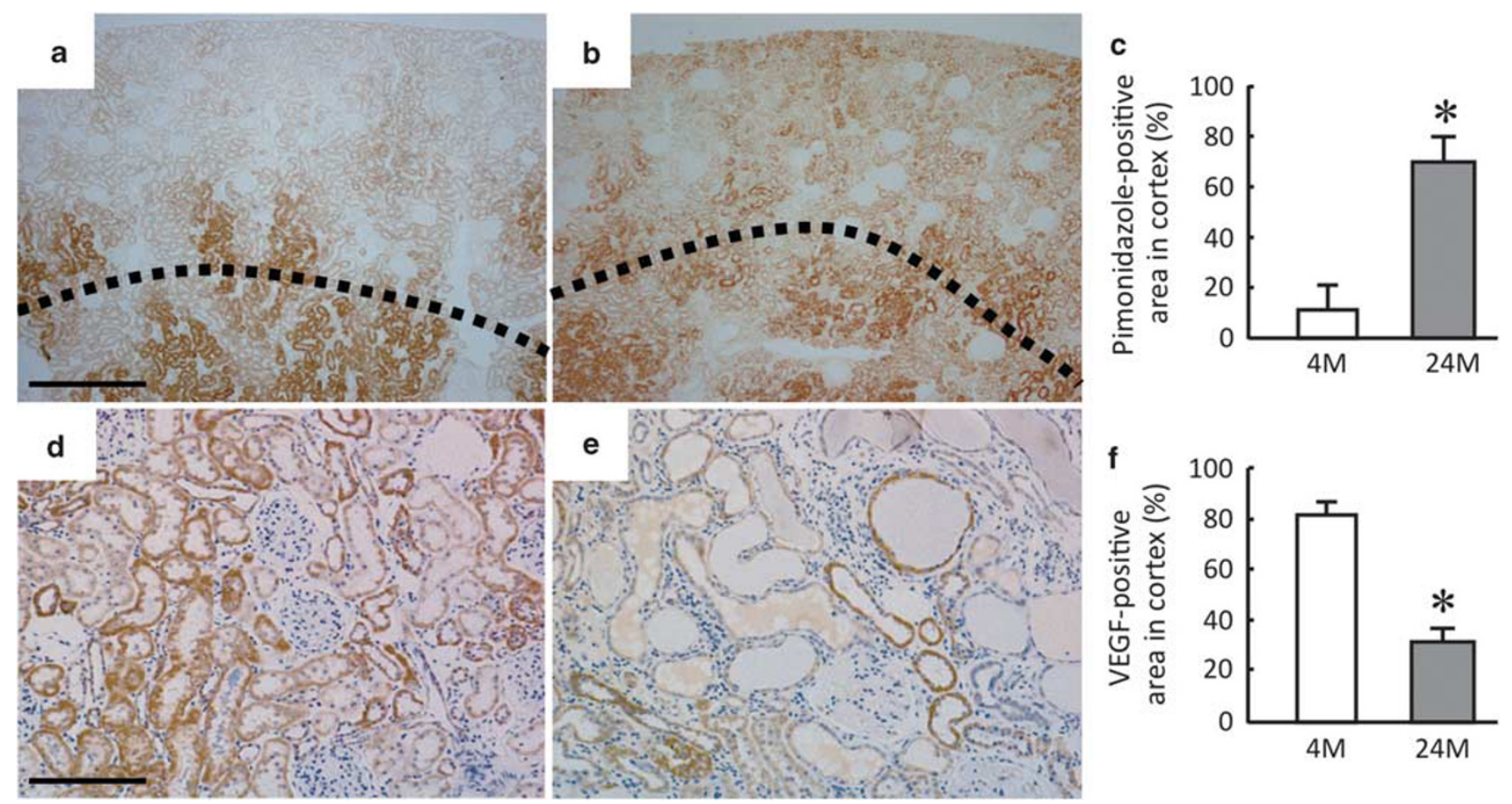

Figure 2 Interstitial hypoxia and expression of vascular endothelial growth factor (VEGF) in aging rat kidney. (a, b) Renal cortical hypoxia detected with pimonidazole staining in 4-month-old $(4 \mathrm{M} ; \mathbf{a})$ and 24 -month-old $(24 \mathrm{M} ; \mathbf{b})$ rats. Dashed line $=$ corticomedullary border. Bar $=0.5 \mathrm{~mm}$. (c) Percent volume of pimonidazole-positive area in renal cortex. (d, e) Immunohistochemical staining for VEGF in the renal cortex in $4 \mathrm{M}$ (d) and $24 \mathrm{M}$ (e) rats. Bar $=100 \mu \mathrm{m}$. (f) Percent volume of VEGF-positive area in renal cortex. $n=10$ for each group. Values are shown as mean \pm s.e.m. ${ }^{*} P<0.05$ versus $4 \mathrm{M}$.

Table 2 Microarray data for VEGF family members and receptors in rat kidney

\begin{tabular}{llc}
\hline Gene & $\begin{array}{l}\text { GenBank } \\
\text { accession number }\end{array}$ & $\begin{array}{c}\text { Gene expression } \\
\text { ratio, 24 months/4 months }\end{array}$ \\
\hline VEGF-A & AF080594 & 0.698 \\
VEGF-B & BF396482 & 0.436 \\
VEGF-C & NM_053653 & 1.328 \\
VEGF-D & AY032728 & 1.118 \\
Placental growth factor & NM_053595 & Low expression \\
VEGF receptor-1 & NM_019306 & 0.926 \\
VEGF receptor-2 & U93307 & 0.643 \\
VEGF receptor-3 & NM_053652 & Low expression \\
\hline
\end{tabular}

Abbrevations: VEGF, vascular endothelial growth factor.

microscopy (Figure 4h and i). Results showed swollen mitochondria in old rat kidney (Figure 4i) with loss of cristae. Some mitochondria were remarkably large.

\section{VEGF Production under Conditions of Mitochondrial Dysfunction}

To investigate the role of mitochondria on VEGF expression induced by hypoxia, we examined VEGF expression after
Table 3 Quantitative real-time PCR data for VEGF family members and receptors in rat kidney

\begin{tabular}{lcc}
\hline Gene & $\begin{array}{c}\text { Gene expression at } \\
4 \text { months } \\
\text { (copy number/r18S) }\end{array}$ & $\begin{array}{c}\text { Gene expression at } \\
24 \text { months } \\
\text { (copy number/r18S) }\end{array}$ \\
\hline VEGF-A & $359 \pm 46 \times 10^{-6}$ & $221 \pm 35 \times 10^{-6}$ a \\
VEGF-B & $692 \pm 38 \times 10^{-7}$ & $296 \pm 27 \times 10^{-7}$ a \\
VEGF receptor-1 & $219 \pm 27 \times 10^{-8}$ & $238 \pm 22 \times 10^{-8}$ \\
VEGF receptor-2 & $736 \pm 45 \times 10^{-8}$ & $486 \pm 28 \times 10^{-8}$ a \\
\hline
\end{tabular}

Abbrevations: VEGF, vascular endothelial growth factor.

Values are expressed as mean \pm s.e.m.

${ }^{\mathrm{a}} P<0.05$ versus 4 months.

$\mathrm{r} 18 \mathrm{~S}$, $18 \mathrm{~S}$ ribosomal RNA; VEGF, vascular endothelial growth factor.

a 24-h hypoxic period in normal hPTECs treated with myxothiazol, a mitochondrial complex III inhibitor (Figure $5 \mathrm{a}$ and c). mRNA expression (Figure $5 \mathrm{a}$ ) and protein secretion (Figure 5c) for VEGF showed a statistically significant increase in response to hypoxia, which was inhibited by pretreatment with myxothiazol. mRNA expression for another HIF target gene, heme oxygenase-1 (HO-1), was also decreased in response to pretreatment with myxothiazol 

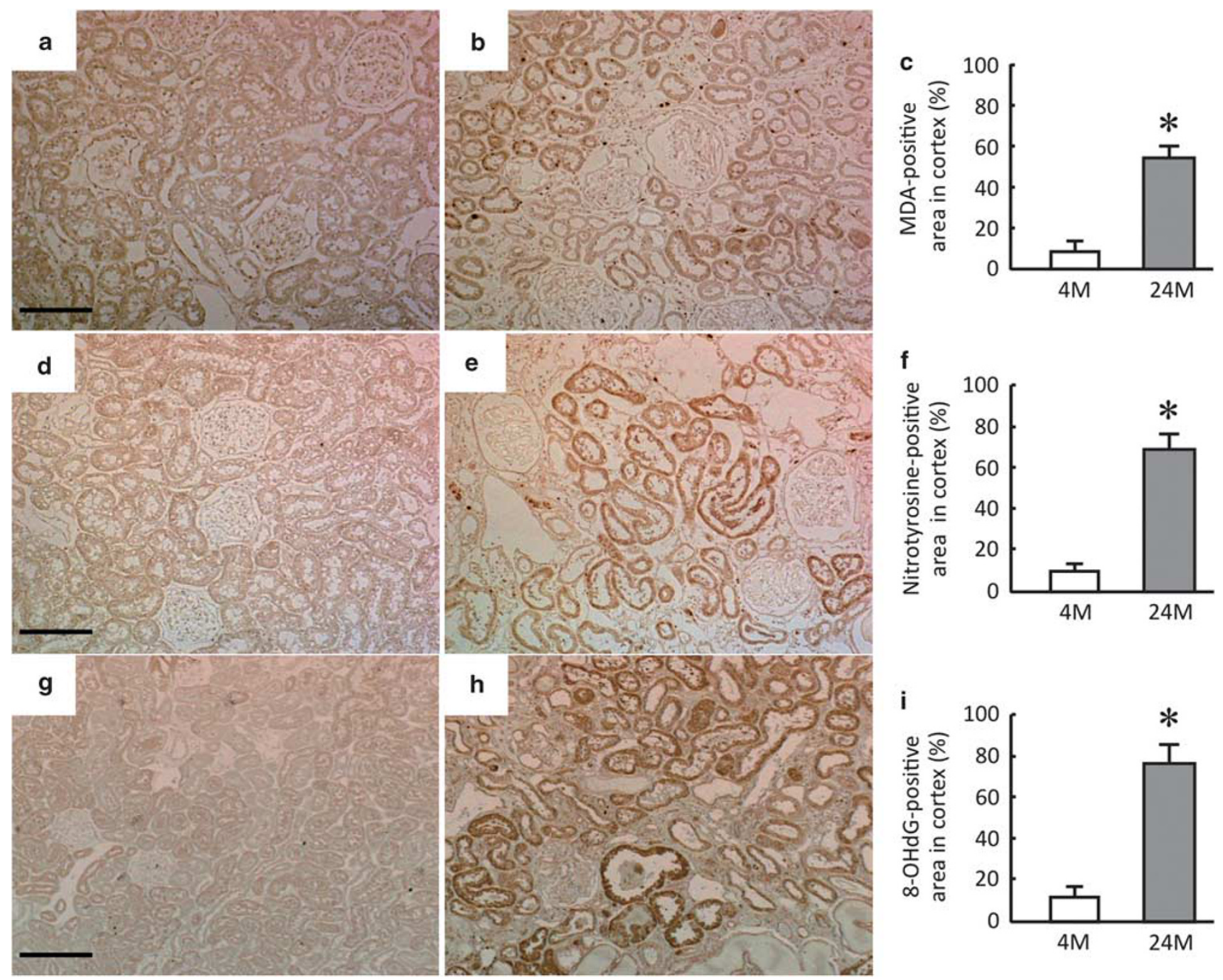
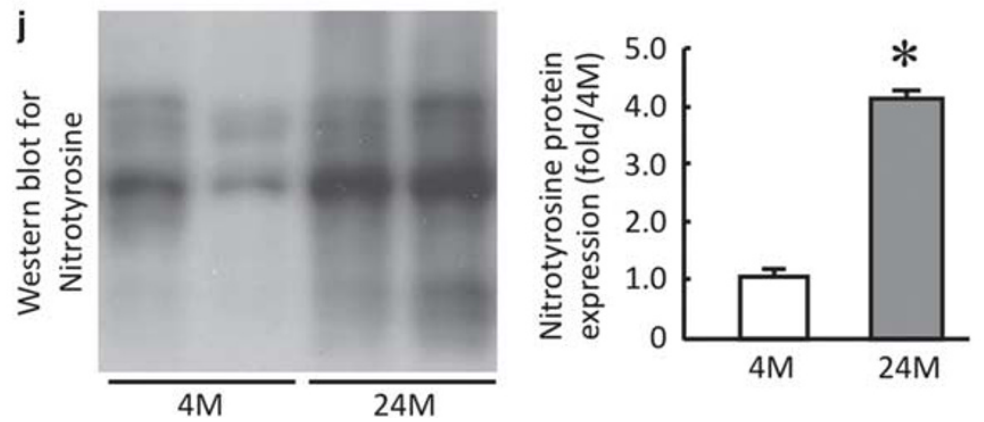

Figure 3 Accumulation of oxidative stress in aging rat kidney. (a, b) Malondialdehyde (MDA) staining in 4-month-old (4M; a) and 24-month-old (24M; b) rat kidneys. Bar $=100 \mu \mathrm{m}$. (c) Percent volume of MDA-positive area in renal cortex. (d, e) Nitrotyrosine staining in $4 \mathrm{M}(\mathbf{d})$ and $24 \mathrm{M}(\mathbf{e})$ rat kidneys. Bar $=100 \mu \mathrm{m}$. (f) Percent volume of nitrotyrosine-positive area in renal cortex. (g, h) 8-Hydroxy-2'-deoxyguanosine (8-OHdG) staining in $4 \mathrm{M}$ (g) and $24 \mathrm{M}$ (h) rat kidneys. $\mathrm{Bar}=100 \mu \mathrm{m}$. (i) Percent volume of 8-OHdG-positive area in renal cortex. $n=10$ for each group. (i) Western blot analysis for nitrotyrosine. Values are expressed as mean \pm s.e.m. ${ }^{\star} P<0.05$ versus $4 \mathrm{M}$.

(Figure 5b). To clarify the role of mitochondria, we next created and examined $\rho 0$ hPTECs. These cells also failed to show increased VEGF expression in response to hypoxia (Figure 5d).

\section{ChIP Analysis of the VEGF Promoter under Hypoxic Conditions}

HIF-1 is a key transcriptional regulator of the VEGF gene. ${ }^{15}$ Therefore, we assessed activation of HIF- $1 \alpha$ by ChIP assay. 
Table 4 Microarray data for antioxidants in rat kidney

\begin{tabular}{llc}
\hline Gene & $\begin{array}{l}\text { GenBank accession } \\
\text { number }\end{array}$ & $\begin{array}{l}\text { Gene expression ratio } \\
\text { 24 months/4 months }\end{array}$ \\
\hline Catalase & NM_012520 & 0.582 \\
Superoxide dismutase 1 & NM_017050 & 0.588 \\
Superoxide dismutase 2 & BG671549 & 0.864 \\
Superoxide dismutase 3 & NM_012880 & 1.832 \\
Thioredoxin reductase 1 & NM_031614 & 0.643 \\
Thioredoxin reductase 2 & NM_022584 & 0.715 \\
Glutathione reductase & NM_053906 & 0.752 \\
\hline
\end{tabular}

\section{Table 5 Quantitative real-time PCR data for antioxidants in} rat kidney

\begin{tabular}{lcc}
\hline Gene & $\begin{array}{c}\text { Gene expression at } \\
4 \text { months } \\
\text { (copy number/r18S) }\end{array}$ & $\begin{array}{c}\text { Gene expression at } \\
24 \text { months } \\
\text { (copy number/r18S) }\end{array}$ \\
\hline Catalase & $446 \pm 22 \times 10^{-4}$ & $225 \pm 28 \times 10^{-4}$ a \\
Superoxide dismutase 1 & $240 \pm 31 \times 10^{-4}$ & $83 \pm 23 \times 10^{-4}$ a \\
Superoxide dismutase 2 & $104 \pm 21 \times 10^{-5}$ & $36 \pm 2 \times 10^{-5}$ a \\
Superoxide dismutase 3 & $302 \pm 53 \times 10^{-5}$ & $435 \pm 75 \times 10^{-5}$ \\
Thioredoxin reductase 1 & $616 \pm 64 \times 10^{-6}$ & $138 \pm 11 \times 10^{-6}$ a \\
Thioredoxin reductase 2 & $306 \pm 61 \times 10^{-7}$ & $118 \pm 13 \times 10^{-7}$ a \\
Glutathione reductase & $118 \pm 29 \times 10^{-6}$ & $43 \pm 2 \times 10^{-6}$ a
\end{tabular}

Values are expressed as mean \pm s.e.m.

${ }^{\mathrm{a}} P<0.05$ versus 4 months.

$\mathrm{r} 18 \mathrm{~S}, 18 \mathrm{~S}$ ribosomal RNA.

Specific primers containing 2 HIF- $1 \alpha-$ binding sites were designed for the VEGF promoter (Figure 6a). The ChIP assay was performed using an antibody specific for HIF- $1 \alpha$. Results showed that the primer set could detect HIF- $1 \alpha$ activation in response to a 4-h hypoxic period (Figure 6b). Mitochondrial dysfunction induced by pretreatment with myxothiazol or in $\rho 0$ hPTECs showed reduced HIF- $1 \alpha$ activation in response to hypoxia (Figure 6c).

\section{Effect of Mitochondrial Dysfunction in Response to Hypoxia on P38 MAPK and AMPK}

To determine the precise mechanisms of HIF- $1 \alpha$ activation, we examined the activities of p38 MAPK and AMPK because both pathways are involved in VEGF expression in response to HIF- $1 \alpha$ activation ${ }^{16,17}$ or stabilization of VEGF mRNA. ${ }^{18}$ In normal hPTECs, p38 MAPK was activated by a 2-h hypoxic period (Figure 7a). However, no p38MAPK activation was observed in myxothiazol-treated hPTECs or $\rho 0$ hPTECs. AMPK activity was also impaired in myxothiazol-treated
hPTECs and $\rho 0$ hPTECs compared with normal hPTECs (Figure $7 \mathrm{~b}$ ).

\section{DISCUSSION}

The purpose of this study was to determine whether mitochondrial dysfunction in the aged rat kidney results in impaired angiogenesis and tubulointerstitial damage. Results showed increased tubulointerstitial damage and loss of proximal tubular cells and an increase in the cortical hypoxic area, but no increase in VEGF expression, in aged rat kidney. In addition, oxidative stress to the tubules was increased, mRNA expressions of the genes encoded by mtDNA were decreased, and mitochondrial morphological changes and dysfunction were observed. We also showed that mitochondrial dysfunction resulted in impairment of HIF- $1 \alpha$-dependent VEGF expression in response to hypoxia in cultured hPTECs. These results indicate that mitochondrial dysfunction blocks VEGF upregulation and contributes to impaired angiogenesis in the aging rat kidney.

We observed a decrease in VEGF expression in the aging kidney despite loss of proximal tubular cells and tissue ischemia. Several factors may be involved in the loss of proximal tubular cells, resulting in a situation in which the kidney is unable to undergo repair, owing to aberrant angiogenesis. Angiogenesis is a compensatory response of ischemic tissue to a lack of blood flow and oxygen supply. Compensatory angiogenesis appears to be restricted in the aging kidney. Decreases in angiogenic factors, increases in antiangiogenic modulators, and/or decreases in circulating endothelial progenitor cells may contribute to impaired angiogenesis. Decreased VEGF expression ${ }^{5}$ and increased thrombospondin 1 expression, ${ }^{19}$ as well as that of pigment epithelium-derived factor, ${ }^{20}$ a major inhibitor of angiogenesis, have been reported in the aging kidney. In addition, it has reported that the numbers of circulating endothelial progenitor cells, which have significant roles in neovascularization of ischemic tissues, decrease with aging and become dysfunctional. ${ }^{21,22} \mathrm{~A}$ recent report indicated that chronic hypoxia attenuates VEGF signaling and angiogenic responses by downregulation of VEGF receptor 2 in human endothelial cells. ${ }^{23}$ We confirmed that VEGF receptor 2 expression in the aging rat kidney was decreased compared with that in young rat kidney. This may provide a novel explanation for impaired angiogenic responses to VEGF in the aging kidney.

We observed an accumulation of oxidative stress in the aged rat kidney. Because mtDNA lacks the structural protection of histone protein or DNA-binding proteins, it readily undergoes oxidative damage in comparison to nuclear DNA. In addition, mitochondria are one of the main intracellular sources of oxidants under physiological conditions. Thus, oxidative modification and mutation of mtDNA occur readily, and the extent of such alterations increases with age. $^{24}$ Disorders of mtDNA produce abnormalities in mitochondrial morphology and function. ${ }^{25,26}$ Our present 

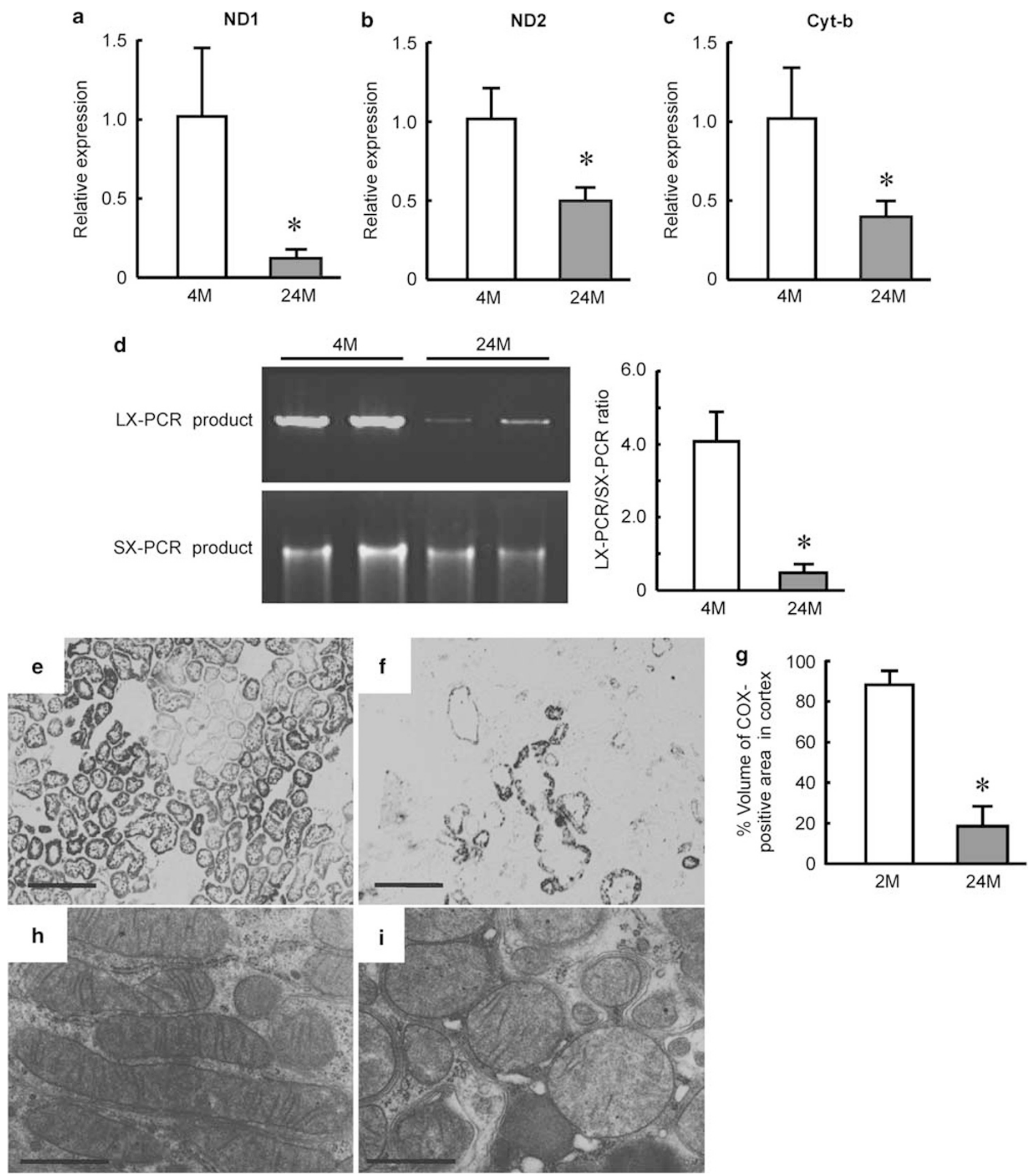

Figure 4 Mitochondrial damage in aging rat kidney. (a-c) mRNA expression of mitochondrial component, nicotinamide adenine dinucleotide dehydrogenase subunit 1 (ND1; a), nicotinamide adenine dinucleotide dehydrogenase subunit 2 (ND2; b), and cytochrome $b$ (Cyt-b; c) by quantitative realtime PCR. $n=10$ for each group. Data are expressed as mean \pm s.e.m. ${ }^{\star} P<0.05$ versus 4 -month-old (4M). (d) Long-extension (LX)-PCR and short-extension (SX)-PCR of mtDNA. $n=6$ for each group. Data are expressed as mean \pm s.e.m. ${ }^{*} P<0.05$ versus 4 M. (e, $\mathbf{f}$ ) Mitochondrial function as assessed by histochemistry for cytochrome $c$ oxidase $(C O X)$ in $4 \mathrm{M}(\mathbf{e})$ and 24 -month-old $(24 \mathrm{M} ; \mathbf{f})$ rat kidneys. Bar $=100 \mu \mathrm{m}$. (g) Percent volume of COX-positive area in renal cortex. $n=10$ for each group. Data are expressed as mean \pm s.e.m. ${ }^{\star} P<0.05$ versus 4 M. (h, i) Electron microscopic images of mitochondria in tubular cells in $4 \mathrm{M}(\mathbf{h})$ and $24 \mathrm{M}$ (i) rat kidneys. Bar $=1 \mu \mathrm{m}$. 
a

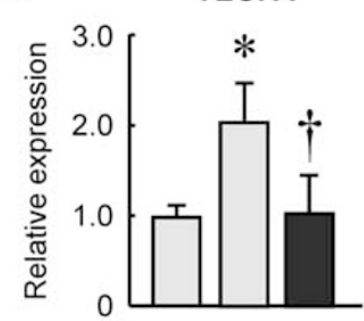

Hypoxia - + +

Myxothiazol - -+

C

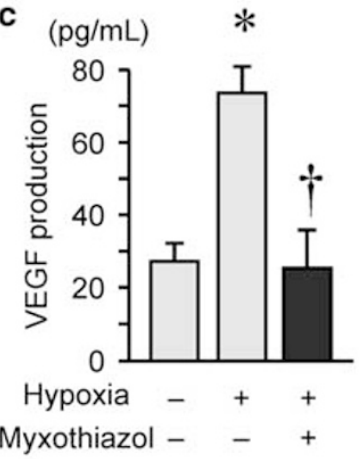

b

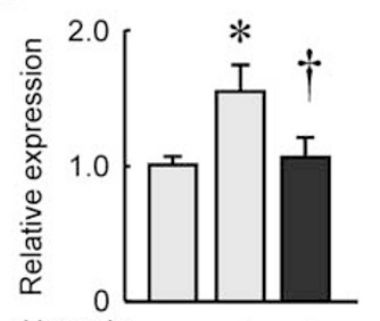

Hypoxia - + + Myxothiazol - -+

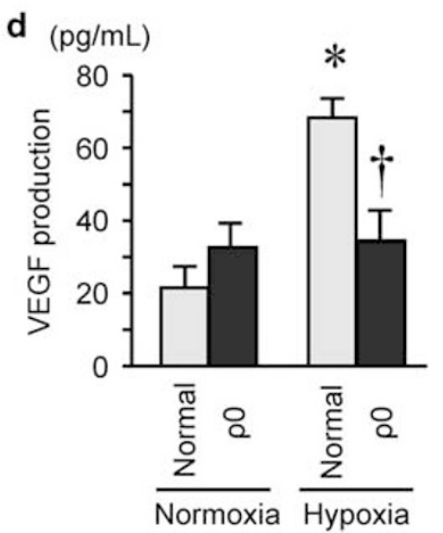

Figure 5 Expression of vascular endothelial growth factor (VEGF) in renal proximal tubular cells induced by hypoxia for $24 \mathrm{~h}$. (a, b) Effect of myxothiazol, an inhibitor of mitochondrial complex III, on hypoxia-inducible factor target gene, VEGFA (a), and heme oxygenase-1 (HO- 1 ; b). $n=6$ for each group. Data are expressed as mean \pm s.e.m. ${ }^{\star} P<0.05$ versus hypoxia ( - ) and myxothiazol (-). ${ }^{\dagger} P<0.05$ versus hypoxia ( + ) and myxothiazol (-). (c) Effect of myxothiazol, an inhibitor of mitochondrial complex III, on VEGF excretion. $n=6$ for each group. Data are expressed as mean \pm s.e.m. ${ }^{*} P<0.05$ versus hypoxia ( - ) and myxothiazol ( - ). ${ }^{\dagger} P<0.05$ versus hypoxia $(+)$ and myxothiazol (-). (d) Effect of mitochondria on VEGF production. Normal $=$ normal renal proximal tubular cell; $\rho 0=\rho 0$ tubular cell; normoxia $=21 \% \mathrm{O}_{2} ;$ hypoxia $=2 \% \mathrm{O}_{2} . n=6$ for each group. Data are shown as mean \pm s.e.m. ${ }^{*} P<0.05$ versus normal at normoxia. ${ }^{\dagger} P<0.05$ versus normal at hypoxia.

results showed increases in functional and morphological disorder of mitochondria in aged rat kidney. Dysfunction in antioxidant ability is also related to the accumulation of oxidative stress. In the present study, we showed decreases in the expression of antioxidant genes with age. It has been reported that prevention of oxidative stress by antioxidant treatment also prevents age-related decreases in mitochondrial membrane potential and increases in mitochondrial size. ${ }^{25}$ Therefore, antioxidant therapy might be useful for the preservation of mitochondrial function.

Mitochondrial damage can occur as a consequence of the disease processes. Therefore, maintaining a healthy population of mitochondria is essential for the well-being of cells. Autophagic delivery to lysosomes is the major degradative pathway for mitochondrial turnover. ${ }^{27}$ Therefore, processing of abnormal mitochondria decreases, and the number of abnormal mitochondria within cells increases with declining autophagic function. The decline in autophagic activity results in tissue and functional disorders of the aging process. In aging cardiac myocytes, imperfect autophagic mitochondrial turnover results in the abnormal accumulation of mitochondria within myocytes, loss of contractility, and decreased survival time in culture. ${ }^{28}$ However, there is a contradicting report that autophagy in the heart and liver do not decrease with age in ad libitum-fed rats and is enhanced by caloric restriction in the heart. ${ }^{29}$ There are few reports examining autophagy in the aging kidney. Our examination showed that the expression of beclin 1, which has a significant role in autophagy, ${ }^{30}$ was increased compared with that in young rat kidney (Supplementary Figure 3). These results indicated that the mechanism of autophagy was normal in the aged rat kidney.

Our present in vitro results showed that mitochondria were essential for VEGF expression through HIF- $1 \alpha$ activation in response to hypoxia, consistent with a report that the generation of mitochondrial ROS is necessary for hypoxic activation of HIF-1. ${ }^{31}$ Activation of HIF-1 is important for VEGF-induced angiogenesis, and mitochondria are involved in HIF-1 activation. Inhibition of mitochondrial function reverses hypoxia-induced HIF-1 activation, leading to speculation of a role for mitochondria in cellular oxygen sensing. Inhibition of mitochondrial complex III by antimycin A1 inhibits HIF-1 activation and angiogenesis by a decrease in VEGF expression. ${ }^{32}$ Activation of HIF-1 leads to the expression of a variety of adaptive genes in a coordinated manner. Studies utilizing HIF-1-stimulating agents showed efficacy in various kidney disease models, suggesting that HIF-1 activation is an ideal target for future therapeutic approaches. ${ }^{33-35}$ We predict that renal damage may worsen as a result of mitochondrial disorders unless HIF-1 is activated. Impaired angiogenesis in response to mitochondrial dysfunction may be one of the basic conditions for renal damage in the aging kidney.

The most important role of mitochondria is the production of ATP. Mitochondria produce ATP by oxidizing pyruvate and nicotinamide adenine dinucleotide, which are produced in the cytosol during glycolysis. ${ }^{6}$ Mitochondrial dysfunction may lead to deficits in cellular energy and compromise vital ATP-dependent cellular operations, including detoxification, repair systems, DNA replication, and the osmotic balance. Kidney function is highly dependent on the mitochondrial ATP supply; hence, the kidneys are particularly susceptible to declines in mitochondrial energy production. Under severe hypoxic conditions, mitochondrial ATP production ceases, leaving cells dependent entirely on their glycolytic metabolism. Thus, a decrease in ATP synthesis in response to mitochondrial impairment might result in a hampered response to mild or moderate hypoxia.

In the present study, we showed that AMPK and p38 MAPK activation in response to hypoxia was abolished in $\rho 0$ hPTECs and in myxothiazol-treated hPTECs. AMPK and p38 MAPK are stress-activated protein kinases, and their 


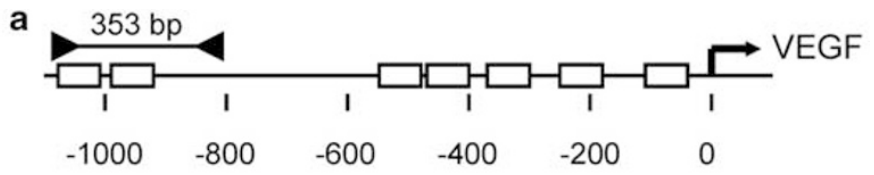

Hypoxia response element; (G/C/T)ACGTGC(G/T)
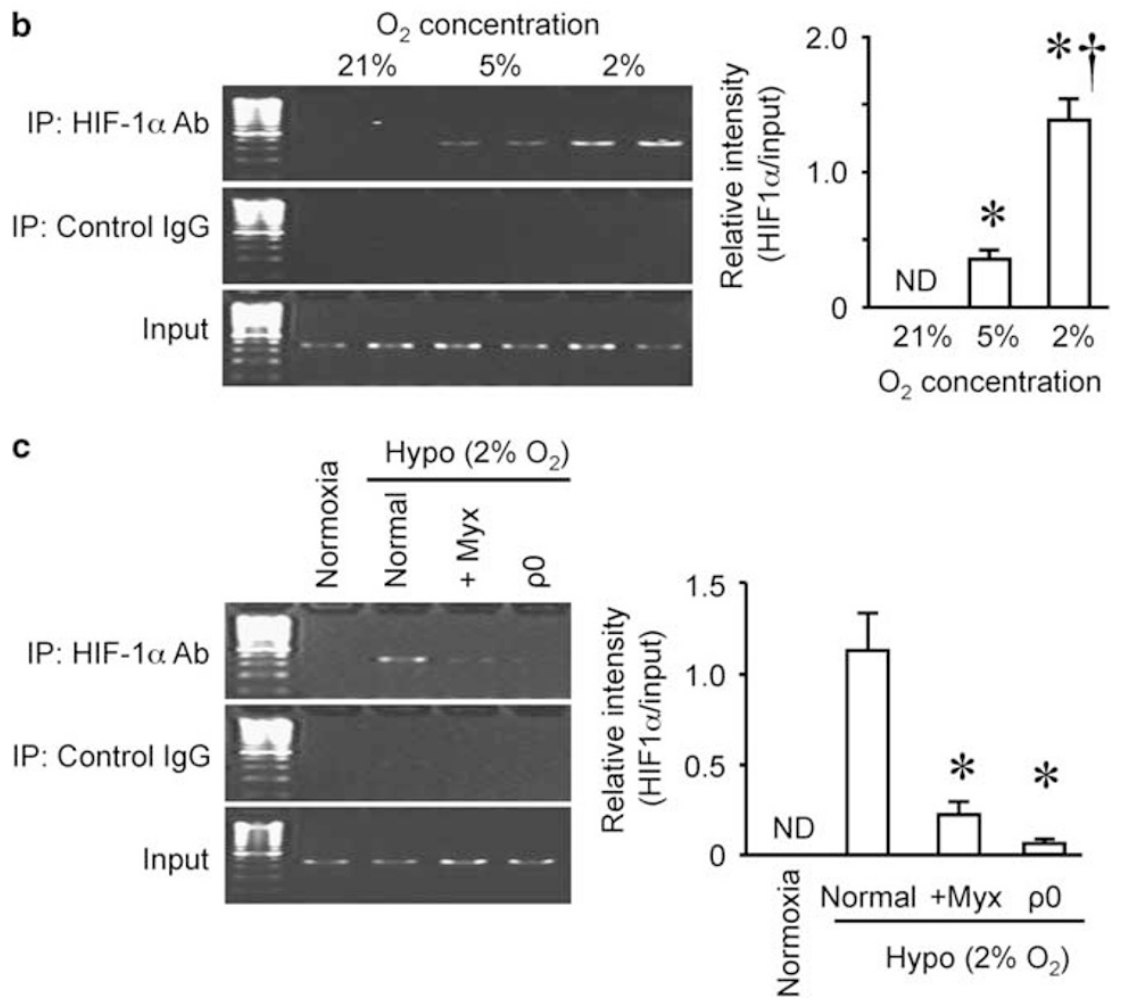

Figure 6 Chromatin immunoprecipitation (ChIP) analysis of vascular endothelial growth factor (VEGF) promoter after hypoxia for $4 \mathrm{~h}$. (a) Schematic for primers. Specific primer sets of VEGF promoter region containing two hypoxia-inducible factor (HIF)-1 $\alpha$ binding sites $(-1140$ to -788$)$ were used. (b) Hypoxia-induced HIF-1 $\alpha$ activation. A ChIP (IP) assay was performed using an antibody specific for HIF- $1 \alpha$. Rabbit normal IgG was used as a negative control. $n=6$ for each group. Data are shown as mean \pm s.e.m. $\mathrm{ND}=$ not detected. ${ }^{\star} P<0.05$ versus $21 \% \mathrm{O}_{2} .{ }^{\dagger} P<0.05$ versus $5 \% \mathrm{O}_{2}$. (c) Mitochondrial damage decreased HIF- $1 \alpha$ activation in response to hypoxia. Normoxia $=21 \% \mathrm{O}_{2} ;$ normal $=$ normal tubular cell; + Myx $=$ myxothiazol-treated normal proximal tubular cell; $\rho 0=\rho 0$ tubular cell. $n=6$ for each group. Data are expressed as mean \pm s.e.m. ${ }^{\star} P<0.05$ versus normal cell at $2 \% \mathrm{O}_{2}$.

signaling in endothelial cells is essential for angiogenesis in response to hypoxic stress. ${ }^{36}$ AMPK-p38 MAPK signaling stimulates VEGF expression by increasing VEGF mRNA stability. ${ }^{18}$ Under hypoxic conditions, AMPK activity is also critical for HIF-1 transcriptional activity and its target gene expression. ${ }^{17}$ Phosphorylation of $\mathrm{p} 38$ MAPK is also required for hypoxia signaling. ${ }^{16}$ In $\rho 0$ endothelial cells, the amount of phosphorylated AMPK in response to hypoxia is decreased, ${ }^{37}$ indicating that mtDNA is required for AMPK activation. In addition, the hypoxic activation of p38 MAPK and HIF-1 is abolished by myxothiazol, a mitochondrial complex III inhibitor, ${ }^{16}$ suggesting that the mitochondrial respiratory chain is necessary for a normal response to hypoxia.

ROS of the mitochondrial respiratory chain are important for activation of HIF-1 in hypoxia. Mitochondria increase their generation of ROS through complex III during hypoxia. ${ }^{9}$ These ROS participate in signal transduction pathways involved in adaptive responses, including ischemic preconditioning and gene transcription. Damaged mitochondria increase ROS production, resulting in the accumulation of oxidative stress. The question is whether these ROS participate in cell signaling. The vicious cycle theory postulates that typical mtDNA mutations cause host mitochondria to generate more superoxide anion and other ROS than normal mitochondria, thereby promoting the occurrence of additional mtDNA mutations at an accelerating rate. However, nearly all reported loss-of-function mtDNA mutations studied in vivo are large deletions, which (as the original statement of the theory noted, but which has been widely overlooked) should not trigger a vicious cycle because they will prevent the assembly of superoxide-generating enzyme complexes. ${ }^{38}$ Swelling mitochondria show low membrane potential and low ATP production. Along with the decrease in mitochondrial membrane potential, ROS production, dependent on a normal proton concentration gradient, is low. Therefore, it is thought that impaired ROS 
a
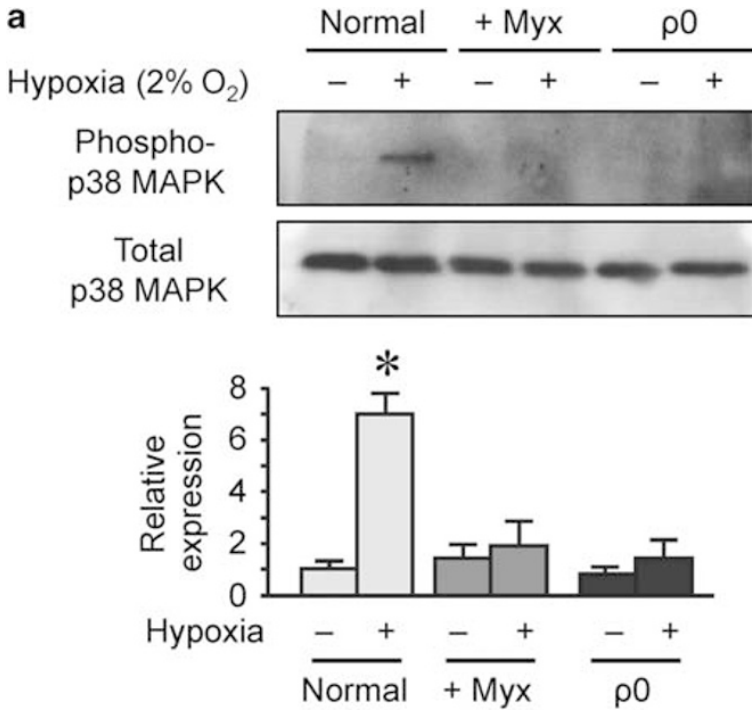

b
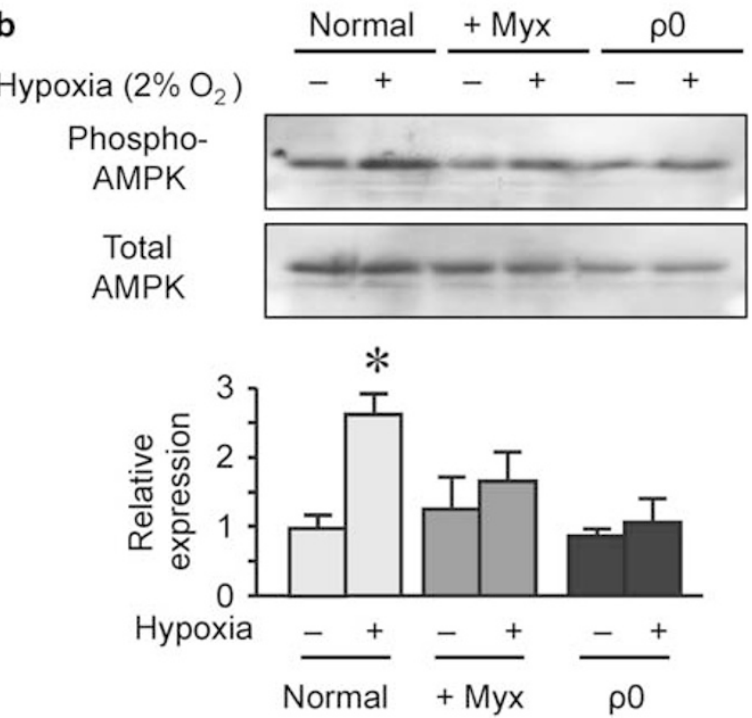

Figure 7 p38 mitogen-activated protein kinase (MAPK) and AMP-activated protein kinase (AMPK) activation in response to 2-h hypoxia. (a) Western blot analysis for p38 MAPK activation using an antibody specific for phospho-p38 MAPK. (b) Western blot analysis for AMPK activation using an antibody specific for phospho-AMPK. normal $=$ normal tubular cell; $+\mathrm{Myx}=$ myxothiazol-treated normal proximal tubular cell; $\rho 0=\rho 0$ tubular cell. $n=6$ for each group. Data are expressed as mean \pm s.e.m. ${ }^{\star} P<0.05$ versus normal at hypoxia (-).

production exists in abnormal mitochondria under hypoxic conditions in the aged kidney.

To prevent or decrease age-related renal damage, it appears that protection of mitochondria against oxidative stress is important. Angiotensin receptor blockers (ARBs) have been reported to decrease mitochondrial dysfunction. For example, renal mitochondrial dysfunction in spontaneously hypertensive rats was attenuated by treatment with the ARB losartan. ${ }^{39}$ de Cavanagh et al reported that mitochondrial dysfunction and mitochondrial ultrastructural changes occur in aged rat kidney, and these changes are prevented by the ARB losartan. ${ }^{40}$ In that study, the authors suggested that the association of ARBs with oxidative stress modulation might be effective in mitochondrial protection. We also showed the existence of mitochondrial respiratory chain damage and morphological change in aged kidney and also showed that these impairments result in low reactivity for hypoxia in aged kidney. Treatment with ARBs might be effective in improving impaired angiogenesis in aged kidney.

Renal injury itself could cause mitochondrial damage. Therefore, it is difficult to distinguish whether mitochondrial damage is the cause or result of renal damage. Tubulointerstitial fibrosis causes tubular hypoxia, which is the cause of age-associated mitochondrial dysfunction ${ }^{41}$ and is involved in age-dependent tissue damage affecting the kidney. ${ }^{42}$ However, if cell protective reactions against hypoxia work normally, renal tubular cells would survive, and renal damage would not progress. We demonstrated that impaired mitochondrial respiratory function causes low expression of cell-protective HIF target genes, such as VEGF or HO-1 against hypoxia in tubular cells. Therefore, mitochondrial damage may be one of the exacerbation factors for renal injury, not the main cause of age-related renal damage.

We did not directly show that mitochondrial dysfunction mediates the impaired hypoxic response to VEGF production in the aged rat kidney. Additional studies are needed to elucidate the precise role of impaired angiogenesis and its regulation in the aging kidney. Nonetheless, the present results indicate that dysfunctional mitochondria accumulate in the aged kidney in association with an increase in oxidative stress, probably owing to a decrease in antioxidant activity. This mitochondrial alteration altered cellular VEGF expression in response to hypoxia. Indeed, impaired upregulation of VEGF, possibly induced by mitochondrial dysfunction, contributes to impaired angiogenesis, which in turn leads to renal injury in the aging rat kidney. Protection of mitochondria against oxidative stress may be a useful strategy for the preservation of renal function in the aging kidney.

Supplementary Information accompanies the paper on the Laboratory Investigation website (http://www.laboratoryinvestigation.org)

\section{ACKNOWLEDGEMENTS}

This study was supported by the Mitsui Life Social Welfare Foundation (MS), the Ryobi Teien Memory Foundation (MS), the Research Project Grant from Kawasaki Medical School (No. 20-2130 to MS), and Grants-in-Aid for Scientific Research from the Japan Society for the Promotion of Science (No. 21591047 to NK). We thank Ms Sawako Tsujita, Ms Mayumi Ono, and Ms Satomi Hanada (Kawasaki Medical School) for animal care and technical assistance.

\section{DISCLOSURE/CONFLICT OF INTEREST}

The authors declare no conflicts of interest.

1. Hemmelgarn BR, Zhang J, Manns BJ, et al. Progression of kidney dysfunction in the community-dwelling elderly. Kidney Int 2006;69: 2155-2161. 
2. Go AS, Chertow GM, Fan D, et al. Chronic kidney disease and the risks of death, cardiovascular events, and hospitalization. N Engl J Med 2004;351:1296-1305.

3. Fried LF, Shlipak MG, Stehman-Breen C, et al. Kidney function predicts the rate of bone loss in older individuals: the Cardiovascular Health Study. J Gerontol A Biol Sci Med Sci 2006;61:743-748.

4. Abrass CK, Adcox MJ, Raugi GJ. Aging-associated changes in renal extracellular matrix. Am J Pathol 1995;146:742-752.

5. Kang DH, Anderson S, Kim YG, et al. Impaired angiogenesis in the aging kidney: vascular endothelial growth factor and thrombospondin-1 in renal disease. Am J Kidney Dis 2001;37:601-611.

6. McBride HM, Neuspiel M, Wasiak S. Mitochondria: more than just powerhouse. Curr Biol 2006;16:R551-R560.

7. Ortega-Saenz P, Pardal R, Garcia-Fernandez M, et al. Rotenone selectively occludes sensitivity to hypoxia in rat carotid body glomus cells. J Physiol 2003;548:789-800.

8. Guzy RD, Schumacker PT. Oxygen sensing by mitochondria at complex III: the paradox of increased reactive oxygen species during hypoxia. Exp Physiol 2006;91:807-819.

9. Klimova T, Chandel NS. Mitochondrial complex III regulates hypoxic activation of HIF. Cell Death Differ 2008;15:660-666.

10. Kanwar YS, Liu ZZ, Kumar A, et al. D-glucose-induced dysmorphogenesis of embryonic kidney. J Clin Invest 1996;98:2478-2488.

11. Satoh M, Kashihara N, Fujimoto $S$, et al. A novel free radical scavenger, edarabone, protects against cisplatin-induced acute renal damage in vitro and in vivo. J Pharmacol Exp Ther 2003;305:1183-1190.

12. Satoh M, Fujimoto $S$, Arakawa $S$, et al. Angiotensin II type 1 receptor blocker ameliorates uncoupled endothelial nitric oxide synthase in rats with experimental diabetic nephropathy. Nephrol Dial Transplant 2008;23:3806-3813.

13. Mansouri A, Gaou I, De Kerguenec C, et al. An alcoholic binge causes massive degradation of hepatic mitochondrial DNA in mice. Gastroenterology 1999;117:181-190.

14. King MP, Attardi G. Human cells lacking mtDNA: repopulation with exogenous mitochondria by complementation. Science 1989;246: 500-503.

15. Semenza GL. HIF-1 and human disease: one highly involved factor. Genes Dev 2000;14:1983-1991.

16. Emerling BM, Platanias LC, Black E, et al. Mitochondrial reactive oxygen species activation of p38 mitogen-activated protein kinase is required for hypoxia signaling. Mol Cell Biol 2005;25:4853-4862.

17. Lee M, Hwang JT, Lee HJ, et al. AMP-activated protein kinase activity is critical for hypoxia-inducible factor- 1 transcriptional activity and its target gene expression under hypoxic conditions in DU145 cells. J Biol Chem 2003;278:39653-39661.

18. Ouchi N, Shibata R, Walsh K. AMP-activated protein kinase signaling stimulates VEGF expression and angiogenesis in skeletal muscle. Circ Res 2005;96:838-846.

19. Olson BA, Day JR, Laping NJ. Age-related expression of renal thrombospondin 1 mRNA in F344 rats: resemblance to diabetes induced expression in obese Zucker rats. Pharmacology 1999;58: 200-208.

20. Pina $A L$, Kubitza $M$, Brawanski $A$, et al. Expression of pigmentepithelium-derived factor during kidney development and aging. Cell Tissue Res 2007;329:329-338.

21. Rauscher FM, Goldschmidt-Clermont PJ, Davis BH, et al. Aging, progenitor cell exhaustion, and atherosclerosis. Circulation 2003;108: 457-463.

22. Edelberg JM, Tang $\mathrm{L}$, Hattori $\mathrm{K}$, et al. Young adult bone marrowderived endothelial precursor cells restore aging-impaired cardiac angiogenic function. Circ Res 2002;90:E89-E93.
23. Olszewska-Pazdrak B, Hein TW, Olszewska P, et al. Chronic hypoxia attenuates VEGF signaling and angiogenic responses by downregulation of KDR in human endothelial cells. Am J Physiol Cell Physiol 2009;296:C1162-C1170.

24. Wei YH. Oxidative stress and mitochondrial DNA mutations in human aging. Proc Soc Exp Biol Med 1998;217:53-63.

25. Sastre J, Millan A, Garcia de la Asuncion J, et al. A Ginkgo biloba extract (EGb 761) prevents mitochondrial aging by protecting against oxidative stress. Free Radic Biol Med 1998;24:298-304.

26. Shigenaga MK, Hagen TM, Ames BN. Oxidative damage and mitochondrial decay in aging. Proc Natl Acad Sci USA 1994;91: 10771-10778.

27. Kim I, Rodriguez-Enriquez S, Lemasters JJ. Selective degradation of mitochondria by mitophagy. Arch Biochem Biophys 2007;462 245-253.

28. Terman A, Dalen $\mathrm{H}$, Eaton JW, et al. Mitochondrial recycling and aging of cardiac myocytes: the role of autophagocytosis. Exp Gerontol 2003;38:863-876.

29. Wohlgemuth SE, Julian D, Akin DE, et al. Autophagy in the heart and liver during normal aging and calorie restriction. Rejuvenation Res 2007; 10:281-292.

30. Liang $\mathrm{XH}$, Jackson $\mathrm{S}$, Seaman $\mathrm{M}$, et al. Induction of autophagy and inhibition of tumorigenesis by beclin 1. Nature 1999;402:672-676.

31. Bell EL, Klimova TA, Eisenbart J, et al. Mitochondrial reactive oxygen species trigger hypoxia-inducible factor-dependent extension of the replicative life span during hypoxia. Mol Cell Biol 2007;27: 5737-5745.

32. Maeda M, Hasebe $\mathrm{Y}$, Egawa $\mathrm{K}$, et al. Inhibition of angiogenesis and HIF-1alpha activity by antimycin A1. Biol Pharm Bull 2006;29: 1344-1348

33. Bernhardt WM, Campean V, Kany S, et al. Preconditional activation of hypoxia-inducible factors ameliorates ischemic acute renal failure. J Am Soc Nephrol 2006;17:1970-1978.

34. Tanaka $T$, Matsumoto $M$, Inagi $R$, et al. Induction of protective genes by cobalt ameliorates tubulointerstitial injury in the progressive Thy 1 nephritis. Kidney Int 2005;68:2714-2725.

35. Rosenberger C, Rosen S, Shina A, et al. Activation of hypoxia-inducible factors ameliorates hypoxic distal tubular injury in the isolated perfused rat kidney. Nephrol Dial Transplant 2008;23:3472-3478.

36. Nagata D, Mogi M, Walsh K. AMP-activated protein kinase (AMPK) signaling in endothelial cells is essential for angiogenesis in response to hypoxic stress. J Biol Chem 2003;278:31000-31006.

37. Quintero M, Colombo SL, Godfrey A, et al. Mitochondria as signaling organelles in the vascular endothelium. Proc Natl Acad Sci USA 2006;103:5379-5384.

38. de Grey AD. Reactive oxygen species production in the mitochondria matrix: implications for the mechanism of mitochondrial mutation accumulation. Rejuvenation Res 2005;8:13-17.

39. de Cavanagh EM, Toblli JE, Ferder L, et al. Renal mitochondrial dysfunction in spontaneously hypertensive rats is attenuated by losartan but not by amlodipine. Am J Physiol Regul Integr Comp Physiol 2006;290:R1616-R1625.

40. de Cavanagh EM, Piotrkowski B, Basso N, et al. Enalapril and losartan attenuate mitochondrial dysfunction in aged rats. FASEB J 2003;17:1096-1098.

41. Nohl H, Staniek K, Gille L. Imbalance of oxygen activation and energy metabolism as a consequence or mediator of aging. Exp Gerontol 1997;32:485-500.

42. Tanaka $\mathrm{T}$, Kato $\mathrm{H}$, Kojima $\mathrm{I}$, et al. Hypoxia and expression of hypoxiainducible factor in the aging kidney. J Gerontol A Biol Sci Med Sci 2006;61:795-805. 